\title{
五一三錄驗實誌雜會究研事醫堂天順
}

三血發丹血名至既炎或亦詳血血

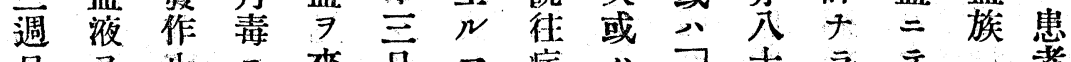

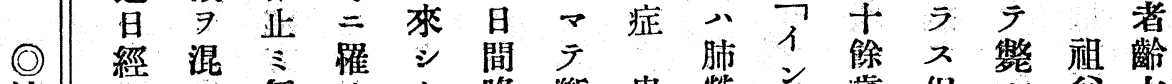

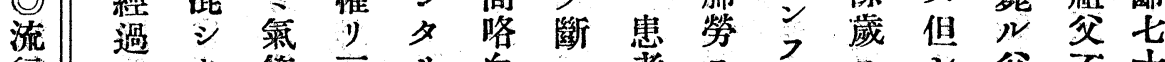

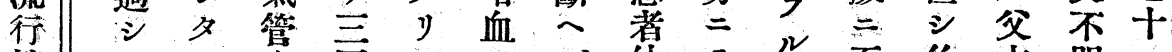

性 夕的支西 シ 七

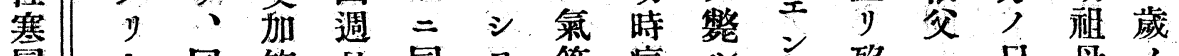

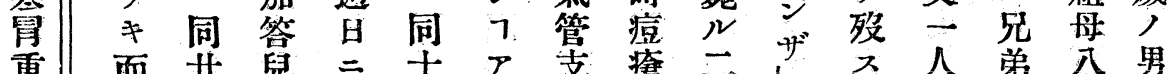

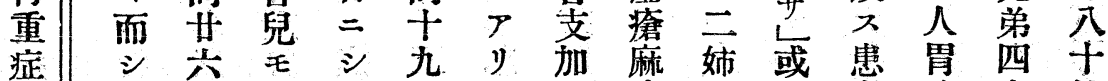

ノテ年亦 テ年爾答 疹一心者癌人 餘

二 最中輕全十來兒 9 妹中同? 各歲

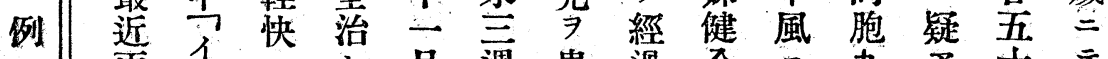

雪 $1=$ 至週患過全

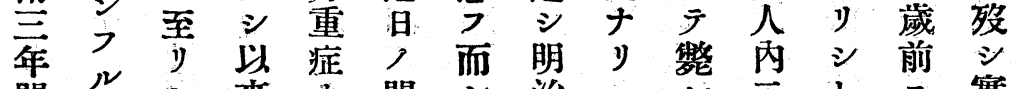

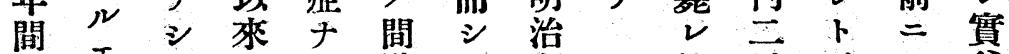

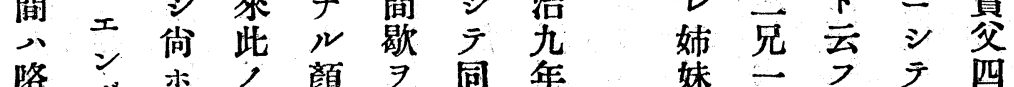

咯䒚示, 顏 7 同年 妹

血

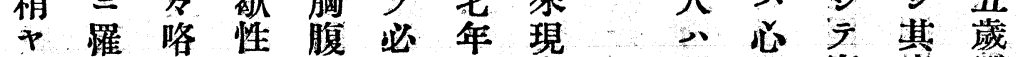

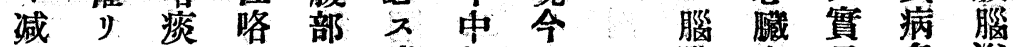

(O)

流

退二=血, 咯偶二膜病母名溢

不

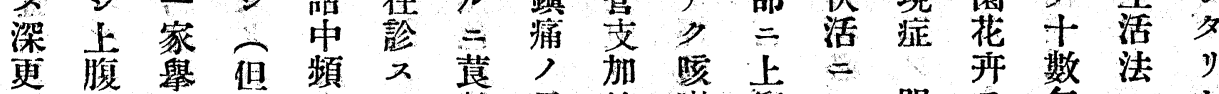

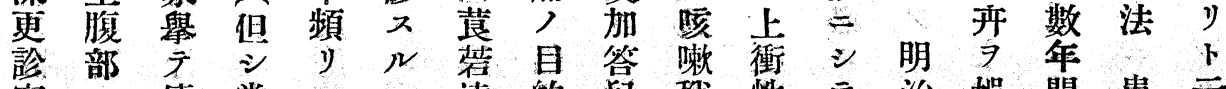

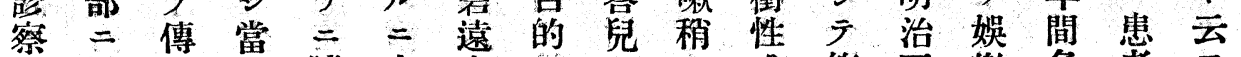

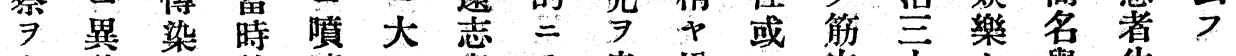

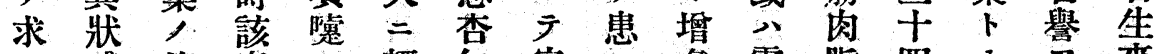

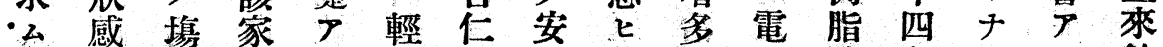

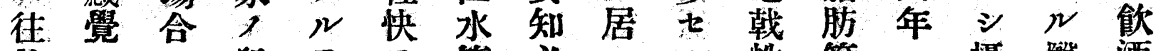

診 $ナ$ 兒 $\ni \rightarrow$ 等 必 $ル$ 性等

ス y y潼以覺, 林 7 , 疼 $大$ 月生官䒜

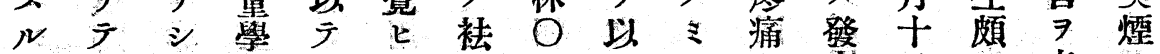

二苦ナ校寒前痰五

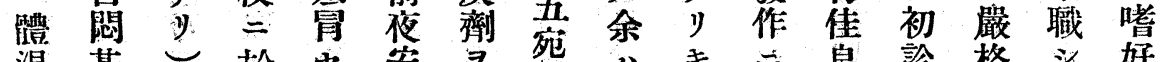

一 盓甚 果於

干 干方然流ナ

五 九毫问行 $\neq$ 得方向, 患體當勁 以 壯

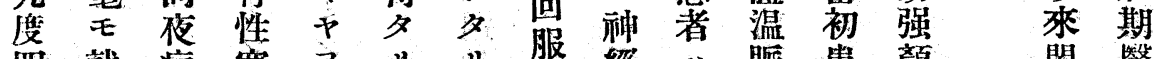

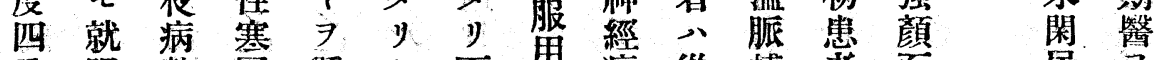

分眼暬舅䀣

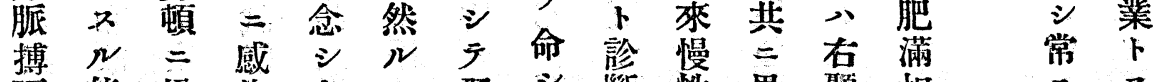

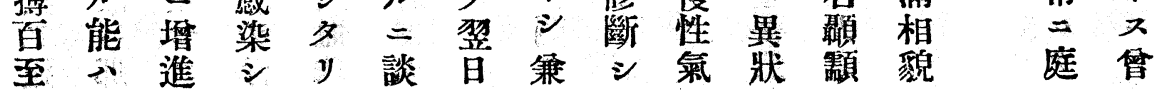




\begin{tabular}{|c|c|c|c|c|c|c|c|c|c|c|c|c|c|c|c|c|}
\hline 管 & ナ & シ & ) & 7 & 次 & 䇾 & 基 & $=$ & 日 & 炎 & 去 & $\rightarrow$ & $\pi$ & $\overline{7}$ & 捣 & 腹 \\
\hline$=$ & $\bar{j}$ & $\bar{y}$ & 尿 & $₹$ & 减 & 兒 & 因 & 至 & 便 & 及 & $\bar{j}$ & 見 & $\nu$ & 前 & 知 & 部 \\
\hline 入 & x & 僅 & 量 & 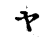 & 退 & 狀 & $\leftarrow$ & リ & 通 & 七 & ᄌ & シ & $=$ & 處 & Ł & $>$ \\
\hline$v$ & 更 & $=$ & + & 1 & 七 & $=$ & $N$ & 黑 & 于 & 氣 & 食 & タ & 珈 & 方 & $\pi$ & 案 \\
\hline 清 & $=$ & 蛋 & $\Xi$ & 疑 & $N$ & $y$ & $E$ & 色 & $\neq$ & 管 & 䔡 & $y$ & 琲 & ) & 自 & 禁 \\
\hline 水 & 粪 & 百 & 日 & 7 & 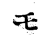 & 更 & , & 糜 & $\Rightarrow$ & 芰 & 閶 & 體 & 狀 & 他 & 䁷 & 鏡 \\
\hline$\exists$ & 便 & , & $n$ & 興 & 苦 & $=$ & $=$ & 3 & 以 & 荻 & 学 & 温 & 暗 & $=$ & 的 & 敏 \\
\hline 淮 & + & 存 & 丞 & サ & 閏 & 臭 & $\boldsymbol{\gamma}$ & 狀 & $\bar{J}$ & 荾 & 不 & $\rightarrow$ & 褐 & 硝 & -1 & 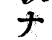 \\
\hline 加 & 七 & 在 & 八 & 3 & 更 & 载 & Э & 便 & 浣 & 3 & 眠 & F & 色 & 喰 & 種 & ラ \\
\hline x & 日 & 7 & 百 & $x$ & $=$ & + & サ & 約 & 腸 & 著 & 倦 & 降 & 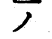 & 重 & 名 & ス \\
\hline K & ' & 認 & 7 & タ & 去 & $\neq$ & U & 六 & $\exists$ & 明 & 意 & $\Xi$ & 痕 & 曹 & 牀 & 特 \\
\hline$\uparrow$ & 分 & $\Delta$ & $=$ & y & $\bar{j}$ & 霬 & 刃 & + & 施 & 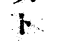 & 頭 & f & 跡 & 菲 & $\pi$ & $=$ \\
\hline 值 & 黑 & $\overrightarrow{3}$ & 7 & y & z & 便 & 如 & 底 & Ł & + & 痛 & 分 & $\gamma$ & 沃 & $\sim$ & 限 \\
\hline 千 & 色 & $\begin{array}{l}1 \\
\text { y }\end{array}$ & 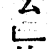 & 排 & 轉 & 7 & $\approx$ & 程 & シ & $y$ & 兩 & 度 & $N$ & 斯 & カ & 局 \\
\hline$=$ & 篰 & $x^{\circ}$ & 比 & 尿 & \& & T & 爾 & T & 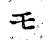 & 旗 & 眼 & 9 & 液 & 等 & ラ & 性 \\
\hline 混 & 兒 & th & 重 & > & 潜 & 泄 & 秝 & 泄 & 顀 & 臟蔵 & 潮 & 示 & 體形 & $\gamma$ & サ & 1 \\
\hline 和 & 狀 & ग & - & 赤 & 伏 & ス & 每 & シ & 便 & 稍 & 紅 & シ & 約 & 散 & $\nu$ & 疼 \\
\hline 純 & ' & $L$ & 0 & 褐 & 性 & $\nu$ & 日 & タ & ' & $\vec{P}$ & 淚 & タ & $\equiv$ & 劑 & 苦 & 痛 \\
\hline 兴 & 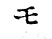 & ノ & $=$ & 色 & 癌 & 7 & $=$ & リ & 通 & 腫 & 液 & リ & + & $\Rightarrow$ & 蕄 & ナ \\
\hline 色 & 3 & 区 & $\Rightarrow$ & $=$ & 腫 & 忩 & 回 & 其 & 利 & 大 & 流 & シ & 庞 & 投 & $P$ & ク \\
\hline$\exists$ & 少 & 應 & 反 & 今 & $=$ & 日 & 宛 & 色 & ナ & $\pi$ & 出 & 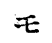 & , & x & y & 且: \\
\hline 呈 & 許 & 亦 & 應 & $\bar{\nearrow}$ & 起 & 間 & 流 & 硝 & シ & 且 & 鼻 & 苦 & 吐 & 翌 & $\checkmark$ & $\%$ \\
\hline シ & 7 & タ & 1 & 溷 & 因 & 體 & 動 & 蒼 & 翌 & $\mathscr{Y}$ & 炎 & 閗 & 出 & 日 & 云 & 腫 \\
\hline 掌 & 試 & 高 & 酸 & 濁 & セ & 輩 & 黑 & 劑 & \$ & 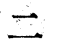 & 咽 & 唒 & 物 & 再 & $\overrightarrow{7}$ & 灌 \\
\hline $\bar{E}$ & 驗 & 度 & $=$ & $\gamma$ & $N$ & 漸 & 色 & $=$ & 日 & $\equiv$ & 喉 & 乐 & 7 & 診 & 㑈 & 7 \\
\hline ラ & 黑 & 化 & 颜 & ト & 每 & 附 & 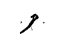 & 其 & 更 & 黑 & 7 & 7 & 又 & 篤 & ス & 血. \\
\hline ザ & 便 & 機 & 定 & 云 & 朝 & $\ddot{\overline{\bar{~}}}$ & 經 & 頃 & $=$ & 色 & 認 & $=$ & 夕 & 倫 & $\mu$ & 色 \\
\hline$\underline{\prime \prime}$ & 中 & 系 & & 7 & 必 & & 過 & $\exists$ & 㱍 & 便 & $x$ & 反 & 基 & 爉 & $=$ & $\overline{3}$ \\
\hline シ & $=$ & $=$ & 余 & & $\pi$ & 嘔 & $=$ & リ & 色 & 第 & ス & 應 & $=$ & 汗 & 黑 & 帶 \\
\hline 力 & $\rightarrow$ & 係 & $>$ & & 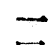 & 㔭 & テ & 漸 & $\overline{7}$ & 亲 & 爾 & 甚 & 少 & 7 & 色 & $\vec{t}$ \\
\hline 是 & 赫 & $v$ & 以 & & 回 & $\therefore$ & 全 & 次 & 呈 & 日 & 來 & 8 & 分 & 加 &, & $\pi$ \\
\hline 亦 & 血: & 重 & t & & 笕 & 前 & $\bar{n}$ & 減 & $\vec{t}$ & 目 & 砂 & 銳 & $\exists$ & $\sim$ & 沈 & 反 \\
\hline 否 & 球 & 症 & I & & $P$ & 後 & 治 & 退 & ス & $\exists$ & 蒼 & 敏 & 自 & 致咸 & 澱 & 應 \\
\hline ラ & 著 & ナ & 症 & & y) & 只 & 癒 & 從 & 正 & y) & 劑 & ナ & $\neq$ & ス & 僅 & 酸 \\
\hline$x$ & シ & 2 & 狀 & & 筫 & タ & : & $\bar{\gamma}$ & 然 & 漸 & $\Rightarrow$ & Y & IIII & $N$ & 力 & 性 \\
\hline 恐 & $n$ & $\neg$ & $=$ & & $\bar{\gamma}$ & $\rightarrow$ & タ & 食 & 每 & 次 & 連 & 而 & $\gamma$ & $=$ & 痕 & $=$ \\
\hline 7 & 分 & 1 & 广 & & 腸 & 回 & $y$ & 㥕 & 朝 & 黄 & 角 & シ & 上 & 赤 & 跤 & シ \\
\hline ラ & 解 & ע & 患 & & 胃 & 7 & & 逐 & 二 & 色 & $x$ & $\bar{\gamma}$ & $=$ & 色 & $=$ & テ \\
\hline$\rightarrow$ & $\mathcal{O}$ & 7 & 者 & & 症 & y & & 日 & 回 & 7 & N & 鏡 & 取 & 万 & 让 & 沈 \\
\hline 硝 & $\bar{\gamma}$ & $\nu$ & Si & & 狀 & シ & & 霄 & 笆 & 帶 & $=$ & 撿 & $y$ & 至 & $\sqrt{2}$ & 湐 \\
\hline 苓 & 血. & 工 & 神 & & $\exists$ & > & & 進 & 通 & E & $t$ & 的 & 7 & 郝 & 少 & 微 \\
\hline 劑 & 質 & $\nu$ & 經 & & 自 & ミ & & x & 利 & 第 & 馀 & 7 & 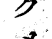 & 褐 & 木 & 少 \\
\hline 服 & $\Rightarrow$ & ザ & 系 & & 覺 & 從 & & $\nu$ & $\gamma$ & $\Xi$ & 香 & 3 & $x$ & 色 & 試 & + \\
\hline 用 & 認 & $L$ & 呼 & & 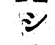 & 前 & & $=$ & y & 週 & ナ & ミ & ( & , & $=$ & $y$ \\
\hline$=$ & $x$ & $\boldsymbol{F}$ & 吸 & & タ & 患 & & 至 & 上 & 日 & $N$ & L & 2 & 沈 & 其 & 硫 \\
\hline 起 & ザ & 認 & 穖 & & $y$ & 著 & & $y$ & 腹 & 1 & $=$ & 結 & 氏 & 澱 & 菎 & 化 \\
\hline 西 & $y$ & 公 & 系 & & $\dot{z}$ & 便 & & 五 & 部 & 終 & 乇 & 晶 & 試 & $\Rightarrow$ & 和 & 水 \\
\hline ス & シ & 而 & 特 & & 7 & 通 & & + & 苦 & $\exists$ & 係 & 及 & 驗 & 生 & 液 & 素 \\
\hline$N$ & $=$ & シ & $=$ & & ナ & 齊 & & 餘 & 聞 & $\boldsymbol{y}$ & ラ & 血 & $\exists$ & Ł & $=$ & $\Rightarrow$ \\
\hline 硫 & $T$ & $\overline{5}$ & 溜 & & 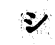 & 然 & & 日 & $\mathcal{E}$ & -1 & $\pi$ & 球 & 行 & $\lambda$ & 那 & 通 \\
\hline
\end{tabular}




\section{七一三 錄驗實誌雜會究研事醫堂天順}

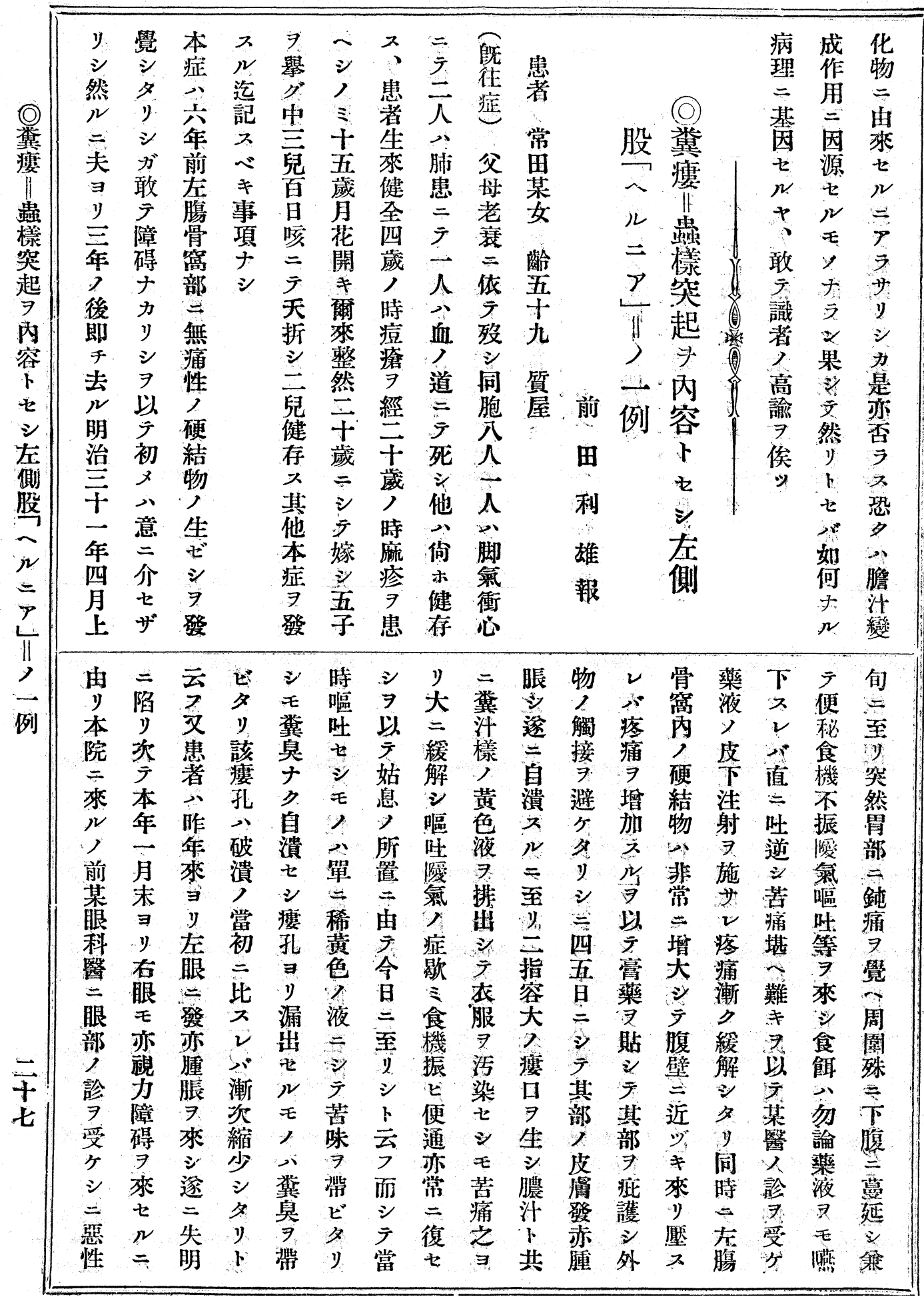

